\title{
A Comparative Study on the Profit Distribution Model of Coal Supply Chain under Inventory Financing
}

\author{
Jia Liu, Chao Sui * \\ School of Economics \& Management, Yanshan University, Qinhuangdao 066004, China \\ liujia3891@163.com,110767609@qq.com \\ *Corresponding author: Chao Sui, 110767609@qq.com
}

\begin{abstract}
The coal supply chain financing cooperation alliance, which is composed of coal producers, coal suppliers, ports and banks, is designed under the inventory financing model. The paper uses the method of Shapley value, simplified MCRS, Game Quadratic Programming to analyze profit distribution of coal supply chain financing cooperation alliance. Taking Qinhuangdao port as an example, conduct application research and comparative analysis of different distribution models. The result shows that the three methods can make optimized decision on the profit distribution of all the members of this coal supply chain financing cooperation alliance under inventory financing. The method of Shapley value can present the fairness of the profit allocation and improve the motivation of coal supply chain financing cooperation alliance.
\end{abstract}

Key words: the coal supply chain; the inventory financing model; coal suppliers; profit distribution

\section{Introduction}

China is the world's largest coal producer and consumer. The upstream coal suppliers often need to be paid to prepay certain loans when ordering coal in the coal supply chain. The upstream coal suppliers must have a certain amount of coal reserves because the downstream dealers demand is random, these have led to coal suppliers facing huge demand for funds. Thus, some port cities have adopted the method of the supply chain finance to solve the financing problem in order to solve coal supplier financing recent years. The paper designed financing coal supply chain alliance dominated by the Port, and selected its own most advantageous method of profit distribution to improve coal suppliers' status and enhance the alliance satisfaction and promote the stable development of alliances

In recent years, supply chain finance has been concerned by the business community and academia as a new business area. In the present, many alliances have not reached the desired effect. many have been forced to disintegration on the road because of profit distribution inequities. So fairly and equitable distribution is growing concern by managers and researchers. Basu(2012) ${ }^{1}$ pointed out that advance financing orders can be easier to solve the problem of logistics lag, followed by the establishment of a dynamic stochastic programming 
model and made a further analysis of the financial feasibility and value. XieShiqing (2013) ${ }^{2}$ summarizes the three typical international supply chain finance, and three models were analyzed and compared, and then mention a lot of comments in order to better development of supply chain finance. Alvin Roth (2007) ${ }^{3}$ made a very large contribution to Cooperative Game and verify the correctness of the Shapley Value. Lejano and Davos (2012) ${ }^{4}$ systematically studies profit distribution using Cooperative Game, and it formed a long-term stable cooperative alliance through equitable distribution method. Chen Wenying (1999) ${ }^{5}$ used Multiplayer Cooperation Game to Optimize investment costs and reffered to GQP method. YueChaoqun (2003) ${ }^{6}$ went from the viewpoint of different fairness or simple calculation about Simplified MCRS. And the author proposed various methods has both advantages and their disadvantages exist. Li Weiqian (2013) ${ }^{7}$ improved Shapley value using DEA Fuzzy Mathematics.

Different from the above-mentioned study, in this paper, The Shapley value, QGP and simplified MCRS profit distribution methods used in the coal supply chain financing alliance. Qinhuangdao Port coal supply chain as an example, the results of each model were compared, and give advice and countermeasures to enhance the alliance satisfaction and stability.

\section{Coal Supply Chain and Inventory Financing Model}

Coal supply chain is composed of coal production enterprises, coal suppliers, ports, downstream coal dealers and end-users. Scope of this paper is limited to profits distribution of the coal suppliers, ports and banks. As shown in dashed lines in Figure 1

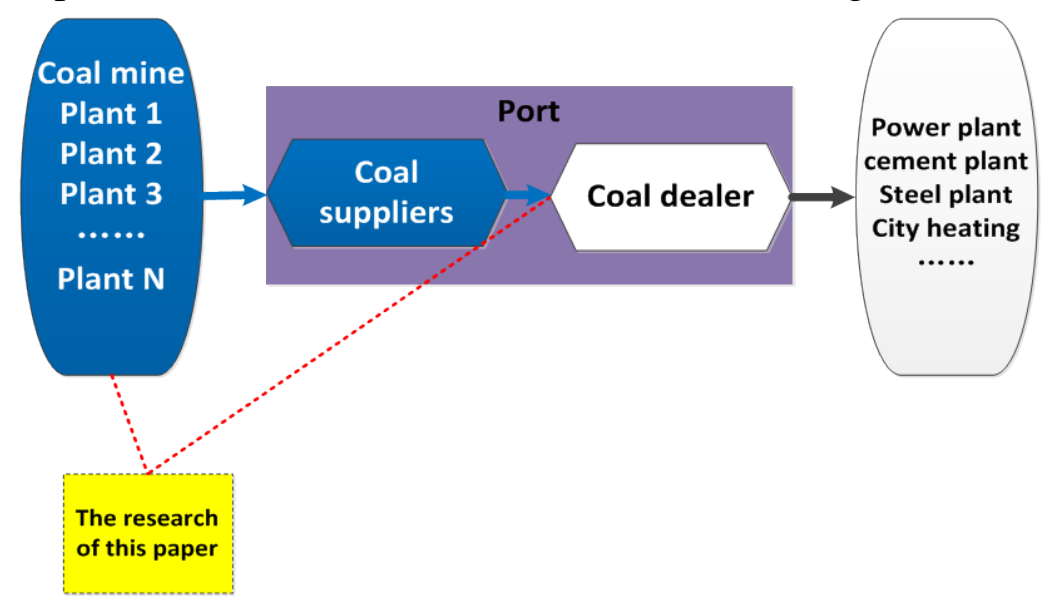

Fig. 1 - Coal Supply Chain under the Guidance of the Port

Coal suppliers are usually vulnerable processing enterprises, such as coal washing, coal blending and so on. it can get the margin through the "buy low and sell high". Because of downstream dealers' random order, coal suppliers have to reserve a certain amount of stock, a lot of inventory led to its poor liquidity, Coal suppliers apply for financing from financial institutions using legitimate coal as pledge. As "outsiders", the bank entrusted ports to check, evaluate and supervise. Banks can credit for coal suppliers after meeting the requirements, 
Inventory pledge will occur until the suppliers are able to repay debt. Ports assured banks, it will sell the inventory coal firstly. Upstream coal mining enterprises assume the risk of security and repurchase. Once the coal suppliers are unable to repay principal and interest due, the bank have the right to dispose of inventory coal.

\section{Several Profit Distribution Models and Its Method}

We will use three methods in this paper: Shapley value, GQP and simplified MCRS.

\subsection{The Profit Distribution Based on the Value of Shapley}

Shapely assumed that a reasonable allocation must meet four axioms, Supply chain financing alliances in the final allocation has nothing to do with the numbering sequence of coal suppliers, banks and port, and this is symmetry. The alliance of profit distribution is equal to total revenue of each subject co-operation, Formulated as $\sum_{i=1}^{n} \psi_{i}(v)=v(N)$, this is the sum nature. The alliance of profit distribution is equal to total revenue of each subject co-operation, Formulated as $\psi_{i}(\mathrm{a}+\mathrm{b})=\psi_{\mathrm{i}}(\mathrm{a})+\psi_{\mathrm{i}}(\mathrm{b})$, this is the sum nature. Coal suppliers, banks, ports and other cooperative alliances and their distribution share in the game is the sum of the assigned amount in the two games, this is additivity. No increase in wealth when participant $\mathrm{i}$ at the supply chain financing alliances, the participant's wealth value is 0 . This is effectiveness.

According four hypotheses, logically proved, $\psi_{i}(v)$ has only solution. The solution is,

$$
\begin{aligned}
\psi_{i}(v) & =\sum_{s \in S_{i}} W(|S|)\left[V(S)-{ }_{V}(S \backslash i)\right], i=1,2, \ldots, n . \\
W(|S|) & =\frac{(n-|S|) !(|S|-1) !}{n !}
\end{aligned}
$$

$S_{i}$ is all collections of subsets including I, $S$ is any element in $S_{i},|S|$ is the number of firms in the league, $w(|S|)$ is the probability of occurrence of different cooperation.

\subsection{Profit Distribution Model Based on GQP Method}

SQP Algorithm calculates the optimal allocation scheme using quadratic programming. The objective function is min $Z=\sum_{i=1}^{n}\left(x_{i}-V_{i}\right)^{2}$, it make the smallest difference between allocation and ideal allocation in coal suppliers, banks and ports. This approach is to make the alliance of each body could identify each other. The restrictions is that the amount of cost-sharing is less than the cost of each individual body and the cost of each subject is less than the cost of the combination of each other. That is solving linear programming problem. 


$$
\begin{aligned}
& \min Z=\sum_{i=1}^{n}\left(X_{i}-V_{i}\right)^{2} \\
& \left\{\begin{array}{l}
\sum_{i=1}^{n} X_{i}=C(N) \\
\sum_{i \in S}^{n} X_{i} \leq C(S)
\end{array}\right.
\end{aligned}
$$

Among them, $x_{i}$ is the cost of i's share in the league and $x_{i} \geq 0, V_{i}$ is the minimum allocation of $\mathrm{i}$ in cooperative alliance, $C(N)$ is the total cost of each individual in cooperative alliance $\mathrm{N}, C(S)$ is the total cost of each individual before the formation of a small alliance $\mathrm{S}$. At last, Seek the value of profit distribution of each individual after entering the League, Formulated as $y_{i}=c_{i}^{b}-x_{i}, y_{i}$ is the value of $\mathrm{i}$ in the Cooperative Alliance, $c_{i}^{b}$ is the individual cost of i before entering the League.

\subsection{Profit Distribution Model Based on Simplified MCRS Method}

At first, the upper and lower bounds of the distribution vector are determined. $X_{\min } \leq x \leq X_{\max }$, the upper bound of the highest income in coal suppliers, banks and ports down as $X_{\max }=\left(\mu_{1}, \mu_{2}, \ldots, \mu_{\mathrm{n}}\right)$, The lower bound down as $x_{\min }=\left(1_{1}, 1_{2}, \ldots, 1_{\mathrm{n}}\right)$, And then by point $x_{\max }$ and $x_{\min }$ connection, hyper plane down as $\sum_{i=1}^{n} X_{i}=C(N)$ the connection and hyper plane's intersection is the solution. Then the simultaneous solution of $x_{i}=x_{\min }+\lambda\left(x_{\max }-x_{\min }\right)$ and $\sum_{i=1}^{n} X_{i}=C(N)$. it can get $\left(\lambda, x^{*}\right)$, Direct definition $x_{\text {max }}=U, x_{\min }=C(N)-C(N-\{i\}), \forall i \in N$, Make coal suppliers, banks, ports, respectively, as the highest and lowest cost sharing. Finally, the profit distribution values: $y_{i}=c_{i}^{b}-x_{i}$.

\section{Empirical analyses}

We assume that there is a coal supplier enterprise A, bank B and Qinhuangdao coal port C. A, $\mathrm{B}, \mathrm{C}$ three parties involved in the supply chain financing of profit distribution. The costs of each individual operating alone are 10 million, 16 million and 15 million respectively. The cost of cooperation between A and B is 14 million, B and C is 18 million, A and C is 15 million, $\mathrm{A}, \mathrm{B}$ and $\mathrm{C}$ is 14 million. When $\mathrm{A}, \mathrm{B}$ and $\mathrm{C}$ operate separately, they can receive 3 million, 4.5 million and 4 million respectively. A and $B$ operating together with a profit of 11 million, A and C is 9 million, B and C is 9.5 million, A, B and C is 18 million, Each 
individual assignment is 6 million when we distribute wealth evenly. But the average allocation method is unreasonable, it cannot mobilize the enthusiasm. So, We use the following three methods to analyze the profit distribution. The results are shown in table 1.

The profit of the cooperation of the coal supplier, the bank and the port is higher than that of not cooperation under the three methods of profit distribution. Therefore, the three parties will tend to enter the cooperation alliance. Also we verified the reasonableness of three kinds of profit allocation method. The results of the comparative analysis of the three kinds of profit distribution are as follows, Firstly, Coal suppliers compared to banks, ports and other strong enterprises is the weak side, The Shapley value are more inclined to the weak side in the supply chain Alliance. The coal suppliers assign value more compared to other methods. It can be seen that the results of Shapley value method need to be further determined by the independence test in the empirical study. Secondly, GQP and simplify MCRS are just the opposite. The strong side, such as banks, ports, etc. will give more alliance revenue distribution, The two methods of profit distribution are based on the contribution of the cooperative alliance, After comparison, found that the results of the two kinds of profit distribution programs are similar, But only considering the comprehensive cooperation of the supply chain financing cooperation, they do not consider the situation of non cooperation. If it formulate distribution programs in the optimal cooperation state, it is more suitable for long-term cooperation in the League. But at present, the individuals of Qinhuangdao port's coal finance cooperation alliance are in a smaller range of pilot cooperation. It is still far from reaching a state of full cooperation in the port coal supply chain. Thus, it can be seen GQP and simplified MCRS a bit less appropriate in Qinhuangdao.

Table 1 - the distribution of A, B and C enterprises under the three methods

\begin{tabular}{cccc}
\hline Distribution model & Coal supplier A & Bank B & Port C \\
\hline Shapley & 575 & 675 & 550 \\
GQP & 466.67 & 766.67 & 566.67 \\
Simplified MCRS & 473.68 & 757.89 & 568.42 \\
\hline
\end{tabular}

All things considered, Although Shapley has the fixed disadvantages, the method's value is based on the average contribution of minor league in cooperation league. It can be seen that, The Shapley can reflect the fairness of the distribution scheme to a great extent, and enhance the enthusiasm of the individual in the supply chain financing cooperation alliance when comprehensive cooperation has not yet reached in the coal supply chain in Qinhuangdao port.

\section{Conclusion}

The results of theoretical study and empirical analysis of coal supply chain revenue distribution model based on Inventory pledge financing are shown as follows. 
Firstly, the inventory pledge financing mode can help to promote the rapid development of coal suppliers and achieve coal suppliers, banks, ports and win-win, It also can increase the revenue of coal suppliers and improve the overall efficiency of the coal supply chain, This financing model is important to the operation and development of coal supply chain.

Secondly, three methods of profit distribution have their own advantages and disadvantages. As to which method of supply chain financing Cooperative Alliance Synergy better, it need to consider the cooperation alliance is the pursuit of fair or efficiency, of course it has to think about the stability of the cooperation alliance, the comprehensive strength of each partner and so on. In this paper, the Shapley introduced correction factor of contribution reflects the relative better than other methods

For the calculation of the model, It is easy to find out through using lingo or MATLAB. but The number of individuals exceeds a certain amount in the supply chain financing cooperation alliance, the calculated value will be difficult to achieve. In reality, the number of individuals has basically reached a dozen, we can refer to various kinds of artificial intelligence methods order to make up for this shortcoming, For example, genetic algorithm, artificial neural network, etc. These methods can get more accurate results if they can be combined with the model in the paper.

\section{Acknowledgements}

I gratefully acknowledge the help of my supervisor, Liu Jia, who has offered me valuable suggestions in the academic studies. I do appreciate her patience, encouragement and professional instructions during my thesis writing. I also want to express my gratitude for the supports by the Hebei Province Social Science Fund Youth Project, contract HB16GL095.

\section{References}

1. P.Basu, S. K.Nair, Supply chain finance enabled early pay, J. International Journal of Logistics Systems and Management, 2012, 12, Mar. 334-353.

2. S.Q. Xie, B. He, Analysis on three typical models of international supply chain finance, J. Economic Theory and Business Management, 2013, Apr. 80-86.

3. I .Erev, A. E. Roth, Multi-agent learning and the descriptive value of simple models, J. Artificial Intelligence, 2007, 171, Jul.423-428.

4. R. P. Lejan, Cost allocation of multi-agency water resource project Game-theoretic approaches and case study, J. Water Resource Research, 2012, 31, 1387-1393.

5. W.Y. Chen, D. Hou, Optimal treatment cost allocation based on multiple-person cooperation game, J. Journal of Environmental Science, 1999, 19,Jan. 57-62.

6. C.Q.Yue, Decision theory and method, M. Beijing: Science Press, 2003.

7. W.Q. $\mathrm{Li}$, Method of allocating ecological compensation amount of river basin based on improved Shapley value, J. Systems Engineering Theory \& Practice, 2013, 33 Jan. 255-261. 